\title{
The effect of physical activity on lymphocyte count in smokers who consume black cumin seed (Nigella sativa L.) oil
}

\author{
Titiek Hidayati ${ }^{1}$, Akrom $^{2}$, Laili Apriani ${ }^{3}$ \\ ${ }^{1}$ Public Health and Family medicine, Medical and Health Science Faculty, Universitas Muhammadiyah \\ Yogyakarta, Indonesia \\ ${ }^{2}$ Department Pharmacology and Clinical Pharmacy, Pharmacy Faculty, Universitas Ahmad Dahlan, Indonesia \\ ${ }^{2}$ Department of Pharmacy, Pharmacy Faculty, Universitas Ahmad Dahlan, Indonesia \\ ${ }^{2}$ Magister Pharmacy Program, Pharmacy Faculty, Universitas Ahmad Dahlan, Indonesia \\ ${ }^{3}$ Ahmad Dahlan Drug Information and Crisis Center, Indonesia
}

\begin{tabular}{l}
\hline \hline Article Info \\
\hline Article history: \\
Received Jan 9, 2020 \\
Revised Feb 7, 2020 \\
Accepted Feb 25, 2020 \\
\hline
\end{tabular}

Keywords:

Black cumin seed oil

Lymphocytes

Physical activity

Randomized controlled trial

Smoker

\begin{abstract}
Twenty percent of the total number of human leukocytes is lymphocytes. Lymphocytes are responsible for the control of the adaptive immune system. Physical activity is any body movement that requires energy to do it. Physical activity is related to changes in a person's immunity so that it can reduce the risks of diseases such as obesity, hypertension, diabetes, cancer, and stroke. Black Cumin Seed Oil (BCSO) in various studies has been widely used as a supplement, especially as an immune-modulator. The purpose of this study is to see the effect of physical activity on lymphocyte levels in smokers who have been given Black Cumin Seed Oil for 30 days. This study used a single-blind Randomized Controlled Trial (RCT) method, with a total of 36 test subjects divided into four groups. Group 1 received placebo $3 \times 1$ capsules/day, group 2 received BCSO $3 \times 1$ capsules/day, group 3 received BCSO $3 \times 2$ capsules/day, and group 4 received BCSO $3 \times 3$ capsules/day. The intervention was carried out for 30 days, then on the 31 st-day blood was drawn for analysis. Data analysis using an independent t-test to see the average group with high and low activity, while to see the average lymphocyte between treatment groups using one way ANOVA test. The test results were said to be significant if $\mathrm{p}<0.05$. The $\mathrm{p}$-value of the independent t-test is 0.045 , and one way ANOVA test p-value is 0.343 . In conclusion, physical activity can increase lymphocyte levels significantly, but not on BCSO administration.
\end{abstract}

This is an open access article under the CC BY-SA license.

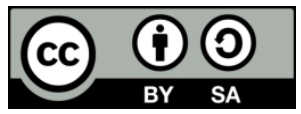

\section{Corresponding Author:}

Akrom,

Department Pharmacology and Clinical Pharmacy,

Faculty Pharmacy,

Universitas Ahmad Dahlan, Yogyakarta, Indonesia.

Email: akrom@pharm.uad.ac.id

\section{INTRODUCTION}

Smoking is associated with many diseases throughout the world [1]. It has been reported that about $1 / 3$ of the adult population are smokers [2]. Cigarette smoke contains many harmful chemicals such as carbon monoxide, nicotine, tar, nitrogen oxides, and cadmium [3, 4]. Smoking dramatically influences the body's immune production and inflammatory mediators, both proinflammatory and anti-inflammatory cytokines [5]. The impact of tobacco could affect innate and adaptive immunity. 
Adaptive immune cells that are affected by smoking are T cells (Th1 / Th2 / Th17), CD4 +, CD25 +, regulatory $\mathrm{T}$ cells, CD $8+\mathrm{T}$ cells, memory $\mathrm{T}$ cells, B cells, whereas innate immune cells that are affected by smoking are DC, macrophages, and NK cells [6]. Cigarettes have to cause diseases such as cancer (lung cancer, bladder cancer, breast cancer), pregnancy (preterm birth, low birth weight, placenta previa), autoimmune disease (rheumatoid arthritis, chronic obstructive pulmonary disease, lupus erythematosus system), neurological disease (Alzheimer's disease, stroke, Parkinson's disease), graft rejection (cardiovascular graft, renal graft, lung transplants), oral and respiratory conditions (asthma, chronic obstructive pulmonary disease, hypersensitivity pneumonitis), cardiovascular diseases (myocardial infarction, cardiac arrhythmia) [7, 8]. The molecular pathway affected by smoking involves NFאB, MAP kinase, and histone modification [9]. Some epidemiological data show that smoking and smoke exposure are associated with polycythemia $[10,11]$. The condition of polycythemia in smokers is an adaptation mechanism to maintain homeostasis due to the reduced amount of partial pressure of O2 in the arteries $[11,12]$.

Lymphocytes are part of leukocytes [13]. Lymphocytes are the main component of the body's immune system consisting of T lymphocytes, B lymphocytes, and NK cells. Lymphocytes are the main body defense agents that work against infection through the phagocytosis process. Lymphocytes also play a role in the immune response against damage caused by smoking. These cells are responsible for producing antibodies, killing cells infected with viruses and tumor cells directly, and regulating the immune response $[12,14]$. The number of lymphocytes is influenced by various conditions, including infection, malignancy, exercises and toxic agents [15].

Physical activity is the movement of the body produced by skeletal muscle that requires energy expenditure [16]. Physical activity has linked to improved immune status and fitness levels [17]. The duration and intensity of physical activity affect blood parameters. Regular physical activity reduces free radicals that are formed in the body after continuous smoking [18]. Physical activity can also improve bone and functional health so that when physical activity decreases, it can weaken the immune system and can cause various diseases and death. Physical and physiological responses also play an essential role in hematology $[19,20]$. However, excessive physical activity has a negative effect, namely causing oxidative stress damage [21].

Black cumin seed oil (Nigella sativa L.) is a medicinal plant that is widely used throughout the world [22]. Black cumin has been commonly used in the treatment of various diseases, including anticancer, hepatoprotective, antimicrobial, analgesic, antidiabetic, anti-inflammatory, immunomodulatory, a bronchodilator, antihypertensive, spasmolytic, and antioxidant [22-25]. Black cumin with the main active ingredient thymoquinone has been reported to have the ability to modulate inflammation, cellular and humoral adaptive immune responses, and the Th1/ Th2 paradigm [26, 27]. Black cumin is also said to be able to increase NK cell cytotoxic activity. Te molecular and cellular mechanisms which underlie the immunomodulatory and anti-inflammatory effects are widely investigated [28]. Until now, how the impact of BCSO consumption on the number of lymphocytes in smokers has not been studied. Based on this description, this study was conducted to determine how the effect of physical activity on lymphocyte levels in healthy volunteers, who are active smokers who have been administered BCSO for 30 days with different doses.

\section{RESEARCH METHOD}

\subsection{Type and design of the study}

This research is an experimental study with a Randomized Controlled Trial (RCT) design. The independent variable in this study is BCSO, while the dependent variable is the level of lymphocytes. Physical activity is identified as a confounding variable. This research was conducted in the working area of the Bantul Jetis I Public Health Center (PHC), in Yogyakarta, in September 2019 to October 2019. Researchers applied the principles of good clinical practice for testing in humans, according to the Helsinki declaration [29].

\subsection{Research subject and intervention}

The population in this study was healthy adult males and smokers. The affordable populations include healthy volunteers, are active smokers, and are in the working area of the Jetis I Primary Health Center (PHC) in Bantul, Yogyakarta. The sampling technique used is purposive sampling, where researchers determine the sample based on predetermined criteria. The Republic of Indonesia Food and Drug Examination Agency has issued a guide on the number of subjects for phase 1 clinical trials, amounting to between 20-50 volunteers [30]. The inclusion criteria in this study were healthy adult males, aged $>18$ years, active smokers, and willing to participate in the study by filling out and signing informed consent. The subjects candidates that have been selected through inclusion criteria will be excluded from 
the study subject if the subject has a history of chronic illness, experiences allergic reactions after administration of BCSO, mental illness, test subjects who did not take part in the study until the end, and were not willing to be present during blood draws on day-to-day 31. Eligible subjects were divided into four groups by simple random sampling. Subjects received a BCSO capsule with three dose ratings or a $3 \times 1$ placebo for 30 days. Reviewing health conditions and side effects is done every day through the smartphone. Every three days, home visits are carried out to count the remaining drugs and measure vital signs.

\subsection{Tools and materials}

The tools and the materials used in this study include primary and secondary data collection sheets using a case report form (CRF), blood collection equipment, and a set of tools for blood analysis. Physical activity data collection was carried out with a universal physical activity questionnaire. Case Report Form (CRF) was used to collect demographic and lifestyle data. While lymphocyte levels were analyzed using Hematology Analyzer. Measurement of vital signs, filling of case report forms (CRF), and nutritional status and blood collection were carried out at the citizen's house. Complete blood measurements were performed at Nur Hidayah Hospital.

\subsection{Variables of research and operational definitions}

The independent variables are BCSO and physical activity, while the dependent variable is lymphocytes. BCSO is available in capsules with a given dosage level of $3 \times 1$ capsules/day, $3 \times 2$ capsules/day, and $3 \times 3$ capsules/day, then compared to the control group who received placebo $3 \times 1$ capsules/day. The physical activities in this study were grouped into two, namely low and high physical activity. In general, data collection in this study was conducted by interview, observation, and direct measurement. Primary and secondary data in the form of patient identity, smoking habits, history of illness, current medical history, and physical activity were collected by structured interviews with questionnaires that were guided and carried out directly in each resident's home.

\subsection{Research procedure}

The instrument used in this study is the case report form (CRF), which is used to obtain primary and secondary data in the form of patient identity, smoking habits, history of illness, current medical history, physical activity, and others. The implementation phase of activities in the field are as follow: (i) The collection of the candidate's subjects test (ii) The candidates subject test who meet the inclusion criteria have explained the research objectives and asked to fill out information sheets as proof of participant's participation in the study. (iii) The subjects who are willing to volunteer are asked to measure their blood pressure, pulse, body temperature, abdominal circumference, weight, and height for the determination of body mass index. (iv) CRF filling is carried out every $2 \mathrm{x}$ monitoring in one week for one month to obtain primary and secondary data. (v) The 31st day the subjects were gathered for blood draws. (vi) Blood that has been taken is then performed a complete blood examination at Nur Hidayah Hospital with a hematology analyzer.

\subsection{Data analysis}

The analysis used to compare the average of lymphocytes between groups is one-way ANOVA, while the analysis to compare the average of lymphocytes in subjects with low and high physical activity is using the independent $t$-test.

\subsection{Research ethics}

Since this study involves human respondents, it is essential to explain to all prospective respondents about the aims and objectives of the study, the expected benefits and uses, and the consequences of the respondent (informed consent), in addition to the management of ethical permits (166/EP-FKIK-UMY/V/2019).

\section{RESULTS AND DISCUSSION}

\subsection{Overview of respondents}

The subject of this study consists of 36 active smokers divided into four treatment groups who are the residents in the work area of the Jetis 1 Public Health Center in Bantul. The demographic conditions of the study subjects according to gender, education, marital status, occupation, smoking status, age, duration of smoking, the amount of cigarette consumption, lymphocytes, and physical activity are presented in Table 1. 
Table 1. Demographic characteristics of respondents

\begin{tabular}{|c|c|c|c|c|c|}
\hline No & Respondents character & istics & Percentage (\%) & Average \pm SD & Total \\
\hline \multirow{3}{*}{1} & \multirow{3}{*}{ Sex } & Male & $100 \%$ & & \multirow{3}{*}{$36(100 \%)$} \\
\hline & & Female & $0 \%$ & & \\
\hline & & Primary School & $11.1 \%$ & & \\
\hline \multirow{3}{*}{2} & \multirow{3}{*}{ Education } & Junior High School & $16.7 \%$ & & \multirow{3}{*}{$36(100 \%)$} \\
\hline & & Senior High School & $58.3 \%$ & & \\
\hline & & $\mathrm{S} 1 / \mathrm{S} 2 / \mathrm{S} 3$ & $13.9 \%$ & & \\
\hline \multirow{3}{*}{3} & \multirow{3}{*}{ Marital Status } & Married & $66.7 \%$ & & \multirow{3}{*}{$36(100 \%)$} \\
\hline & & Not Married & $33.3 \%$ & & \\
\hline & & PNS & $2.8 \%$ & & \\
\hline \multirow{5}{*}{4} & \multirow{5}{*}{ Occupation } & Swasta Nasional & $13.9 \%$ & & \multirow{5}{*}{$36(100 \%)$} \\
\hline & & Small self-employed & $16.7 \%$ & & \\
\hline & & Farmer & $2.8 \%$ & & \\
\hline & & Laborer & $47.2 \%$ & & \\
\hline & & e.t.c & $16.7 \%$ & & \\
\hline \multirow[t]{2}{*}{5} & \multirow[t]{2}{*}{ Smoking Status } & Smoking & $100 \%$ & & \multirow{2}{*}{$36(100 \%)$} \\
\hline & & Not smoking & $0 \%$ & & \\
\hline 6 & Age & & & $38.69 \pm 11.659$ & \\
\hline 7 & Length of smoking (year) & & & $20.92 \pm 10.808$ & \\
\hline 8 & Cigarette Consuming total (stick/day) & & & $10.61 \pm 7.680$ & \\
\hline 9 & Lymphocytes $(\%)$ & & & $35.16 \pm 9.51$ & \\
\hline 10 & Physical Activity (MET/week) & & & $2924.64 \pm 624.575$ & \\
\hline
\end{tabular}

MET/week: Metabolic Equivalent/week

Table 1 shows the characteristics of the respondents used as the test subjects. The gender of the test subjects is male with a percentage $(100 \%)$, the education level is mostly high school graduates $(58.3 \%)$, most of them are married (66.7\%), and the work is dominated by laborers (47.2\%). All of the test subjects are smokers $(100 \%)$. The average age of the test subjects was 38.69 years, the average length of smoking was 20.92 years, the average number of cigarette consumption was 10.61 cigarettes/day, the average lymphocyte level was 35.16\%, and the average physical activity is 2924.64 Metabolic Equivalent/week (MET/week).

\subsection{Analysis of lymphocyte levels between treatment groups}

The number of lymphocytes in healthy volunteer smokers who administered BCSO is presented in Table 2. The average lymphocyte after giving placebo and BCSO for 30 days were the placebo group at $36.58 \%$, the BCSO group $3 \times 1$ by $38.77 \%$, the BCSO group $3 \times 2$ by $34.53 \%$, and the BCSO group $3 \times 3$ by $30.54 \%$. Cigarettes can increase lymphocyte levels according to previous studies [12-14]. Table 3 shows the BCSO dose of $3 \times 3$ capsules/day has the best average lymphocyte, followed by a dose of $3 \times 2$ capsules/day and a dose of 3x1 capsules/day. BCSO has been shown to reduce high lymphocyte levels caused by smoking.

The average levels of lymphocytes that have been obtained are then analyzed with the one way ANOVA test, which has previously fulfilled normality and homogeneity tests to see whether there are significant differences between the groups. Based on the results of the one way ANOVA test in Table 4, the $\mathrm{p}$-value is $0.343>0.05$ which means that there is no significant difference between the average levels of lymphocytes in the placebo group, BCSO 3x1 capsules/day, BCSO 3x2 capsules/day, and BCSO $3 \times 3$ capsules/day. A lymphocyte is the type of white blood cell that is also part of the body's defense system. Normal lymphocyte levels can help prevent and fight various infections; the average value of lymphocytes in the blood is 20-35\%. Lymphocyte levels can be influenced by several things, namely physical activity, bacterial and fungal infections, poor nutritional status, excessive stress, and congenital disabilities.

Table 2. The average lymphocyte number of healthy smoker BCSO administration for 30 days

\begin{tabular}{ccccc}
\hline Group & $\mathrm{n}$ & Lymphocyte average (\%) & Standard Deviation & Sig - (2-tailed) \\
\hline Placebo 3x1 capsules/day (control) & 8 & 36.58 & 7.36 & 0.343 \\
BCSO 3x1 capsule/day & 9 & 38.77 & 9.72 & \\
BCSO 3x2 capsule/day & 11 & 34.53 & 9.74 & 10.50 \\
BCSO 3x3 capsule/day & 8 & 30.54 & 9.51 & \\
Total & 36 & 35.16 & & \\
\hline
\end{tabular}

The analysis of bivariate using one-way ANOVA

If $\mathrm{p}<0.05$ there was a significant difference

\subsection{Analysis of lymphocyte levels between a group of physical activity}

The physical activities in this study are grouped into two, namely low and high physical activity, where the average physical activity becomes a cut point. The average physical activity of the test subjects 
is 2924.64 MET/week. If it is less than the average, it is classified as low activity, whereas if it is more than average, it is classified as the high activity.

Table 3. Independent t-test for lymphocyte levels between the groups of low physical activity and high physical activity.

\begin{tabular}{cccc}
\hline Physical Activity & $\mathrm{n}$ & Lymphocytes average $(\%) \pm$ SD & Sig. (2-tailed) \\
\hline Activity (-) & 21 & $32.4905 \pm 9.47$ & \multirow{2}{*}{$0.045^{*}$} \\
Activity (+) & 15 & $38.89 \pm 8.51$ & \\
*it has a significant difference because $\mathrm{p}<0.05$ & \\
Activity $(-)=$ low physical activity $<2924.64$ & \\
Activity (+) = high physical activity $>2924.64$ &
\end{tabular}

The test subjects with low activity were found with several 21 people and 15 people with high physical activity. The average lymphocyte with low activity was $32.49 \%$, and the average lymphocyte with high activity was $38.89 \%$. The analysis used to compare lymphocyte levels in the low physical activity group with the high activity group is the independent $\mathrm{t}$-test where there is a significant difference if $\mathrm{p}<0.05$. The independent t-test shows the value of sig. (2-tailed) which is equal to 0.045 , which means there is a significant difference between lymphocyte levels in the low physical activity group and high activity group. These results indicate that the increase in lymphocytes along with the high physical activity.

\subsection{Analysis of lymphocyte levels between treatment groups and physical activity}

Table 4 presents lymphocyte counts based on physical activity in healthy smokers volunteer. The physical activity can increase lymphocyte levels can be seen in Table 4 . The average lymphocytes at high activity are more than the average lymphocytes at low activity, but after being analyzed by independent t-test, significant differences were only found in the control group, meaning that the mean od Lymphocytes with high activity are higher than those with low activity without being affected by giving the BCSO. The average lymphocytes in the BCSO group both $3 \times 1,3 \times 2$, and $3 \times 3$ doses with high and low activity there were no statistically significant differences.

Table 4. The average lymphocyte levels of each group with high and low physical activity of the healthy smoker who administered BCSO.

\begin{tabular}{cccc}
\hline Group & High Physical activity + & Low Physical activity - & Sig (2-tailed) \\
\hline Placebo 3x1 capsule/day (control) & $42.700 \pm 6.532$ & $23.400 \pm 4.938$ & $0.046^{\mathrm{a} *}$ \\
BCSO 3x1 capsule/day & $38.960 \pm 5.842$ & $31.350 \pm 5.333$ & $0.720^{\mathrm{a}}$ \\
BCSO 3x2 capsule/day & $39.700 \pm 6.532$ & $31.571 \pm 4.938$ & $0.197^{\mathrm{a}}$ \\
BCSO 3x3 capsule/day & $33.260 \pm 5.842$ & $18.233 \pm 5.333$ & $0.433^{\mathrm{a}}$ \\
Sig (2-tailed) & $0.563^{\mathrm{b}}$ & $0.466^{\mathrm{b}}$ & \\
\hline
\end{tabular}

${ }^{a n}$ independent analysis t-test, there is a significant difference if $\mathrm{p}<0.05$

${ }^{\mathrm{b}}$ one-way ANOVA analysis, there is a significant difference if $\mathrm{p}<0.05$

$*$ there is a significant difference $\mathrm{p}<0.05$

The results of the one way ANOVA analysis were used to see the difference in the average lymphocytes of the four treatment groups at both high and low activities. The p-value for high physical activity is 0.563 , and for low activity is 0.466 , the p-value is higher than 0.05 , so there is no statistically significant difference between lymphocyte levels in each treatment group. Clinically, it can be seen that the higher BCSO dose, the average lymphocyte decreases, this shows BCSO with a dose of 3x3 capsules/day can reduce lymphocyte levels which increase due to cigarette consumption and physical activity to the normal range of $33,260 \%$, while in low physical activity by giving BCSO $3 \times 3$, it reduces lymphocyte levels to below the normal range of $18,233 \%$, so it needs to be adjusted between the amount of cigarette consumption, physical activity and dosage of BCSO, so that lymphocyte levels are in the normal range. The results of the study are in accordance with previous studies that BCSO is tolerated and safe for consumption [31].

\section{CONCLUSION}

The increasing of the lymphocyte levels are associated with a person's smoking condition and excessive physical activity, but by giving BCSO, it can reduce the high lymphocyte levels due to extreme 
physical activity and smoking conditions. The higher the physical activity, the higher the level of a person's lymphocytes as well as the consumption of cigarettes. The higher the BCSO dose, the lymphocyte levels decrease in smokers, so it needs to be adjusted between the amount of cigarette consumption, physical activity, and the treatment of BCSO so that the lymphocyte levels are in the normal range.

\section{REFERENCES}

[1] Z. M. Aljohani et al., "Evaluation of the potential beneficial effects of thymoquinone against nicotine induced toxicity," Int. J. Pharm. Clin. Res., vol. 7, no. 6, pp. 395-398, 2015.

[2] WHO, "Second hand tobacco smoke and children health; Children 's Health and the Environment," 2011.

[3] R. D. Semba, L. M. Kalm, S. De Pee, M. O. Ricks, M. Sari, and M. W. Bloem, "Paternal smoking is associated with increased risk of child malnutrition among poor urban families in Indonesia," Public Health Nutr., vol. 10, no. 1, pp. 7-15, 2007.

[4] S. E. Atawodi, "Tobacco-specific nitrosamines, hemoglobin adducts and exposure to environmental tobacco smoke," Biokemistri, vol. 15, no. 2, pp. 44-49, 2003.

[5] M. Sopori, "Effects of cigarette smoke on the immune system," Nat. Rev. Immunol., vol. 2, no. 5, pp. 372-377, 2002.

[6] K. H. Costenbader and E. W. Karlson, "Cigarette smoking and autoimmune disease: What can we learn from epidemiology?,” Lupus, vol. 15, no. 11, pp. 737-745, 2006.

[7] R. Talhout, T. Schulz, E. Florek, J. van Benthem, P. Wester, and A. Opperhuizen, "Hazardous compounds in tobacco smoke," Int. J. Environ. Res. Public Health, vol. 8, no. 2, pp. 613-628, 2011.

[8] M. B. Reitsma et al., "Smoking prevalence and attributable disease burden in 195 countries and territories, 19902015: A systematic analysis from the global burden of disease study 2015," Lancet, vol. 389, no. 10082, pp. 18851906, 2017.

[9] A. R. Jethwa and S. S. Khariwala, "Tobacco-related carcinogenesis in head and neck cancer," Cancer Metastasis Rev, vol. 36, no. 3, pp. 411-423, 2017.

[10] G. S. Maritz and R. Harding, "Life-long programming implications of exposure to tobacco smoking and nicotine before and soon after birth: Evidence for altered lung development," Int. J. Environ. Res. Public Health, vol. 8, no. 3, pp. 875-898, 2011.

[11] F. S. AlQahtany et al., "Association between cigarette \& shisha smoking and the severity of polycythemia: A cross sectional study," Saudi J. Biol. Sci., vol. 27, no. 1, pp. 460-464, 2019.

[12] K. M. Pedersen, Y. Çolak, C. Ellervik, H. C. Hasselbalch, S. E. Bojesen, and B. G. Nordestgaard, "Smoking and Increased White and Red Blood Cells: A Mendelian Randomization Approach in the Copenhagen General Population Study," Arterioscler. Thromb. Vasc. Biol., vol. 39, no. 5, pp. 965-977, 2019.

[13] G. P. Dunn, L. J. Old, and R. D. Schreiber, "The immunobiology of cancer immunosurveillance and immunoediting," Immunity, vol. 21, no. 2, pp. 137-148, 2004

[14] V. L. Chiasson, D. Talreja, K. J. Young, P. Chatterjee, A. K. Banes-Berceli, and B. M. Mitchell, "Fk506 binding protein 12 deficiency in endothelial and hematopoietic cells decreases regulatory T cells and causes hypertension," Hypertension, vol. 57, no. 6, pp. 1167-1175, 2011.

[15] P. Bellavite, A. Conforti, F. Pontarollo, and R. Ortolani, "Immunology and Homeopathy. 2 . Cells of the Immune System and Inflammation," vol. 3, no. February, pp. 13-24, 2006.

[16] E. L. de Hollander and K. I. Proper, "Physical activity levels of adults with various physical disabilities," Prev. Med. Reports, vol. 10, no. August 2017, pp. 370-376, 2018.

[17] E. Gucciardi, V. W. S. Chan, L. Manuel, and S. Sidani, "A systematic literature review of diabetes self-management education features to improve diabetes education in women of Black African/Caribbean and Hispanic/Latin American ethnicity," Patient Educ. Couns., vol. 92, no. 2, pp. 235-245, 2013.

[18] D. C. Nieman and L. M. Wentz, "The compelling link between physical activity and the body's defense system," $J$. Sport Heal. Sci., vol. 8, no. 3, pp. 201-217, 2019.

[19] M. Dianatinasab et al., "The effect of a 12-week combinational exercise program on CD4 count and mental health among HIV infected women: A randomized control trial," J. Exerc. Sci. Fit., vol. 16, no. 1, pp. 21-25, 2018.

[20] A. K. Buelo, A. Kirk, R. S. Lindsay, and R. G. Jepson, "Exploring the effectiveness of physical activity interventions in women with previous gestational diabetes: A systematic review of quantitative and qualitative studies," Prev. Med. Reports, vol. 14, pp. 100877, 2019.

[21] J. D. Allen, T. Giordano, and C. G. Kevil, "Nitrite and Nitric Oxide Metabolism in Peripheral Artery Disease Introduction and Significance of PAD," vol. 26, no. 4, pp. 217-222, 2013.

[22] H. H. Mollazadeh H, Afshari AR, "Review on the Potential Therapeutic Roles of Nigella sativa in the Treatment of Patients with Cancer: Involvement of Apoptosis:-Black cumin and cancer," J Pharmacopuncture, vol. 20, no. 3, pp. 158-172, 2017.

[23] M. A. Randhawa and M. S. Alghamdi, "Anticancer activity of Nigella sativa (Black Seed) - A review," Am. J. Chin. Med., vol. 39, no. 6, pp. 1075-1091, 2011.

[24] A. Akrom, R. Nurfadjrin, E. Darmawan, and T. Hidayati, "Black Cumin Seed Oil Antidiabetogenic by Increasing Pancreatic P53 Expression,” Int. J. Public Heal. Sci., vol. 7, no. 3, p. 207, 2018. 
[25] T. Hidayati, A. Pramono, I. M. Jenie, and M. H. Soesatyo, "Evaluation of black cumin seeds hexane extract as reactive oxygen intermediates (ROI) and phagocytic activity modulator in DMBA inducedrats," Biomed. Res., vol. 28, no. 4, pp. 1755-1760, 2017.

[26] Akrom and Mustofa, "Black cumin seed oil increases phagocytic activity and secretion of IL-12 by macrophages.," Biomed. Res., vol. 28, no. 12, 2017.

[27] A. F. Majdalawieh and M. W. Fayyad, "Immunomodulatory and anti-inflammatory action of Nigella sativa and thymoquinone: A comprehensive review," Int. Immunopharmacol., vol. 28, no. 1, pp. 295-304, 2015.

[28] A. Ahmad et al., "A review on therapeutic potential of Nigella sativa: A miracle herb," Asian Pac. J. Trop. Biomed., vol. 3, no. 5, pp. 337-352, 2013.

[29] E. A. Joyce, S. J. Popper, and S. Falkow, "Streptococcus pneumoniae nasopharyngeal colonization induces type I interferons and interferon-induced gene expression," BMC Genomics, vol. 10, pp. 404, 2009.

[30] B. 5. Everitt, No Title Statisti(Al Aspkts Of The Dlslgn And Analysls Of (Lini(A1 Trials, 1st ed. London: Imperial College Pres, 2015.

[31] A. Akrom and E. Darmawan, "Tolerability and safety of black cumin seed oil (Bcso) administration for 20 days in healthy subjects," Biomed. Res., vol. 28, no. 9, 2017. 